\title{
Fracture analysis of AZ6-F magnesium composite materials at quasi-superplastic state
}

\author{
M. Besterci ${ }^{1}$, S.-J. Huang ${ }^{2}$, K. Sülleiová ${ }^{1}$, B. Balloková ${ }^{1}$, O. Velgosováa ${ }^{3 *}$ \\ ${ }^{1}$ Institute of Materials Research, Slovak Academy of Sciences, Watsonova 47, 04001 Košice, Slovak Republic \\ ${ }^{2}$ Department of Mechanical Engineering, National Taiwan University of Science and Technology, 43, Sec. 4, \\ Keelung Rd., Taipei 106, Taiwan, R.O.C. \\ ${ }^{3}$ Institute of Materials, Faculty of Metallurgy, Technical University in Košice, \\ Park Komenského 11, 04200 Košice, Slovak Republic
}

Received 2 November 2016, received in revised form 17 February 2016, accepted 21 February 2016

\begin{abstract}
Micromechanisms of fracture of AZ61-F composites in the zone of quasi-superplastic deformation were analysed and quantified in this work. Deformation of AZ61-F magnesium alloys with 1 wt. $\%$ of $\mathrm{Al}_{2} \mathrm{O}_{3}$ phase was tested at a temperature of $473 \mathrm{~K}$ and different strain rates. It was shown that at the temperature of $473 \mathrm{~K}$ and the highest strain rate applied from $1 \times 10^{-2}$ to $1 \times 10^{-4} \mathrm{~s}^{-1}$, a significant growth of ductility was observed. The mean dimples diameter of the ductile fracture decreased with decreasing strain rate. The grain size of $0.7 \mu \mathrm{m}$ was reached by severe plastic deformation using equal channel angular pressing (ECAP). Secondary $\mathrm{Mg}_{17} \mathrm{Al}_{12}$ and $\mathrm{Al}_{2} \mathrm{O}_{3}$ phases were identified. The maximum strain was obtained at the temperature of $473 \mathrm{~K}$ and strain rate of $1 \times 10^{-4} \mathrm{~s}^{-1}$.
\end{abstract}

Key words: AZ61-F Mg- $\mathrm{Al}_{2} \mathrm{O}_{3}$, fracture analysis, quasi-superplastic behaviour, kinetics process

\section{Introduction}

Magnesium alloys are gaining more recognition as the lightest structural materials for lightweight applications, due to their low density and high stiffness-toweight ratio. Even so, $\mathrm{Mg}$ alloys have not been used for critical performance applications because of their inferior mechanical properties, compared to other engineering materials. Nevertheless, there are some practical limitations to using magnesium alloys in industrial applications because these alloys are inherently brittle due to their hexagonal crystal structure and the consequently limited number of active slip systems. An important current requirement is therefore to develop procedures having the potential for improving the ductility of Mg-based alloys. Nowadays it is well established that the processing of fcc metals by the method of the equal channel angular pressing leads to ultrafine grain sizes that are typically within the submicrometer range [1]. If these small grain sizes are reasonably stable at the elevated temperatures, it is possible to achieve a superplastic ductility with elongations to the failure of $>1000 \%[2,3]$. However, it is more difficult to apply ECAP processing to Mg-based alloys successfully. Miyahara et al. [4] experiments were conducted on a commercial AZ61 magnesium alloy to evaluate the potential for achieving the ultrafine grain size and superplastic ductility by the EX-ECAP two-step processing procedure of extrusion plus equal channel angular pressing. The results show that EX-ECAP gives excellent grain refinement with grain size of $\sim 0.6$ and $\sim 1.3 \mu \mathrm{m}$ after pressing at 473 and $523 \mathrm{~K}$, respectively. The alloy processed by EX-ECAP exhibits exceptional superplastic properties including a maximum elongation of $1000 \%$ after pressing through four passes when testing at $473 \mathrm{~K}$ with an initial strain rate of $3.3 \times 10^{-4} \mathrm{~s}^{-1}$.

Hence, many researchers attempt to fabricate $\mathrm{Mg}$ based metal matrix composites by different methods to obtain light-weight materials with excellent mechanical properties [5-8]. Magnesium based nanocomposite $\left(\mathrm{AZ91}-\mathrm{D} \mathrm{Al}_{2} \mathrm{O}_{3}\right)$ was studied in $[9,10]$, where the

*Corresponding author: tel.: +421 55 6022533; fax: +42155602 2770; e-mail address: oksana.velgosova@tuke.sk 
Table 1. Chemical composition of AZ61-F (wt.\%)

\begin{tabular}{lcccccccc}
\hline Elements & $\mathrm{Al}$ & $\mathrm{Mn}$ & $\mathrm{Zn}$ & $\mathrm{Si}$ & $\mathrm{Fe}$ & $\mathrm{Cu}$ & $\mathrm{Ni}$ & $\mathrm{Mg}$ \\
\hline & 5.95 & 0.26 & 0.64 & 0.009 & 0.005 & 0.0008 & 0.0007 & Bal.
\end{tabular}

effect of nano-alumina particles and heat treatment on microstructure, mechanical properties and failure mechanism were investigated.

Superplasticity in polycrystalline materials is facilitated by dynamic modifications in the microstructure. Retrieval of the superplastic microstructure at elevated temperatures rests on the ability to maintain dynamic recovery. The strain rate is defined by Mukherjee equation [11]

$$
\dot{\varepsilon}=\frac{K D G b}{k T}\left(\frac{b}{d}\right)^{p}\left(\frac{\sigma}{G}\right)^{\frac{1}{m}},
$$

where $K$ is constant, $D$ is diffusion coefficient, $G$ is shear modulus, $b$ is Burgers vector, $k$ is Boltzmann constant, $T$ is temperature, $d$ is grain size, $\sigma$ is stress, $p$ is grain size exponent $(2-3)$, and $1 / m$ is stress exponent $(0.4-0.7)$.

The primary deformation mechanism in superplastic materials is a grain boundary sliding with stress accommodation by diffusion or dislocation movement. According to Eq. (1), finer grains (smaller than $10 \mu \mathrm{m}$ ), equiaxed grains with large angle boundaries and higher strain rate are essential to obtain superplasticity at a given stress. Superplasticity is maintained if the dynamic growth of grains is minimised. However, superplasticity can be limited by cavitation on the grain boundaries.

The aim of this paper is to analyse and quantify fracture mechanisms of $\mathrm{AZ61-F}-\mathrm{Al}_{2} \mathrm{O}_{3}$ magnesium system with 1 wt. $\%$ of $\mathrm{Al}_{2} \mathrm{O}_{3}$ phase at a temperature of $473 \mathrm{~K}$ and strain rates of $10^{0}-1 \times 10^{-4} \mathrm{~s}^{-1}$.

\section{Experimental materials and methods}

The matrix used in this work is magnesium alloy AZ61-F made by Metaltech Industrial Co, LTD, Taiwan, the chemical composition is shown in Table 1.

Particles $\mathrm{Al}_{2} \mathrm{O}_{3}$ with the weight fraction of $1 \%$ are used as the reinforcement phase. The commercially available $\mathrm{Al}_{2} \mathrm{O}_{3}$ powder with a particle diamete $\mathrm{r}$ about $20 \mathrm{~nm}$ with the purity of $\geq 99.8 \%$ is added into AZ61-F to form Mg-based metal-matrix composites.

The melt-stirring technique was used to fabricate the present $\mathrm{Mg}$ composites. The AZ61-F and $\mathrm{Al}_{2} \mathrm{O}_{3}$ particles were initially placed inside a graphite crucible and heated to $673 \mathrm{~K}$ in a resistance-heated furnace; then a stirring vane functioned; meanwhile, $\mathrm{CO}_{2}$

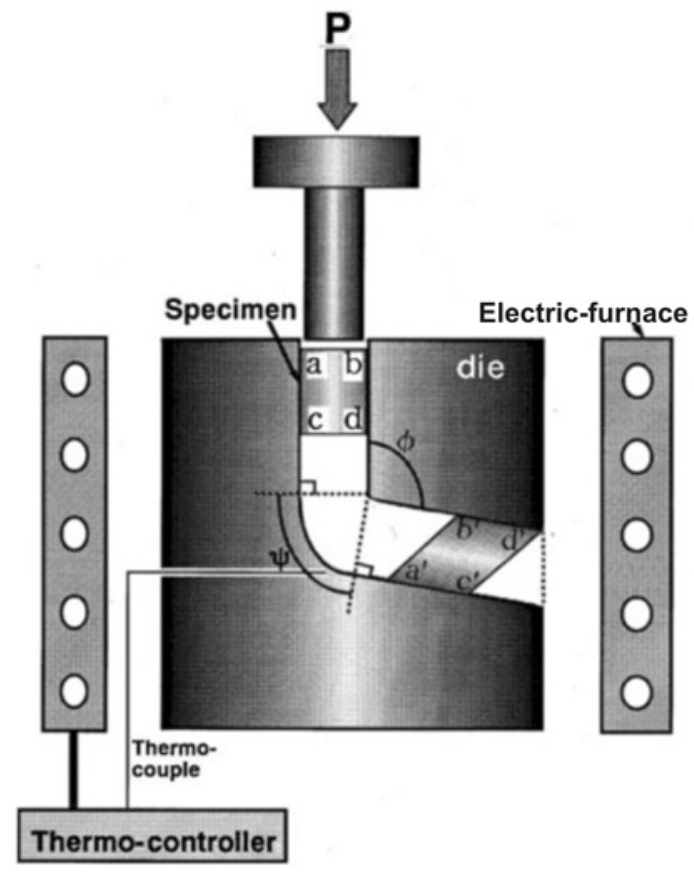

Fig. 1. Scheme of the equal-channel angular pressing (ECAP).

and $\mathrm{SF}_{6}$ gushed from the gas tank into the crucible to mix the melt. $\mathrm{CO}_{2}$ and $\mathrm{SF}_{6}$ also prevented the melt from oxidation. The crucible was continuously heated up to $973 \mathrm{~K}$, and then the molten alloy was stirred with a vane operated at $350 \mathrm{rev} \mathrm{min}^{-1}$ for $3 \mathrm{~min}$. Finally, the composite melt was poured into a metallic mould.

The $\mathrm{Mg}$ composite containing 1 wt. $\%$ of $\mathrm{Al}_{2} \mathrm{O}_{3}$ was prepared for further mechanical testing. ECAP was carried out in a die with the die angle of $\Phi=120^{\circ}$. The scheme of ECAP is shown in Fig. 1. The deformation temperature was set at $573 \pm 10 \mathrm{~K}$. During deformation, the plunger speed was about $1.0 \mathrm{~mm} \mathrm{~s}^{-1}$. After each extrusion pass, the billet was quenched into water. The billets were rotated counterclockwise around the exit extrusion axis by $90^{\circ}$ between each pass, the so-called Bc route, and each bar was ECAPed by 4 passes. From these alloys, specimens ( $\varnothing 3$ and $30 \mathrm{~mm}$ long) were prepared for tensile testing.

\section{Results and discussion}

Microstructure parameters of the system, namely the matrix grain size, the mean size of the dispersed particles and their average distance before and after ECAP were evaluated. The microstructure of the starting material (before ECAP) was heterogeneous with the grain size of $25-30 \mu \mathrm{m}$. The grain size of material after ECAP was observed by TEM, Fig. 2. In 


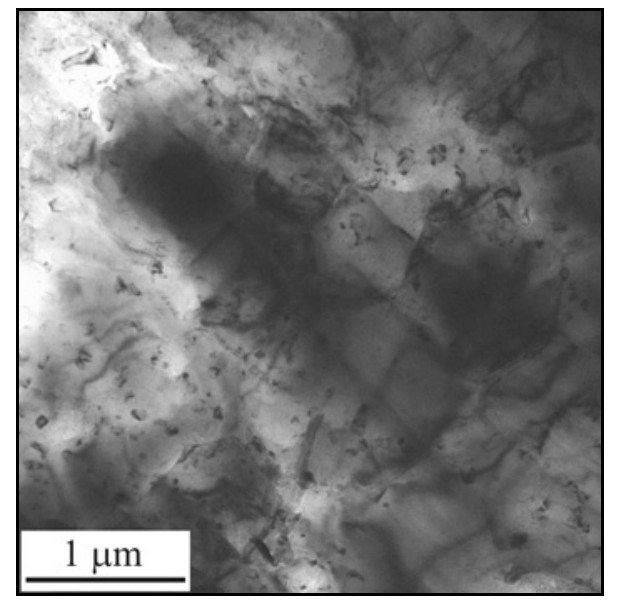

Fig. 2. TEM photo of grain sizes and distribution of $\mathrm{Al}_{2} \mathrm{O}_{3}$ particles, the material after ECAP.

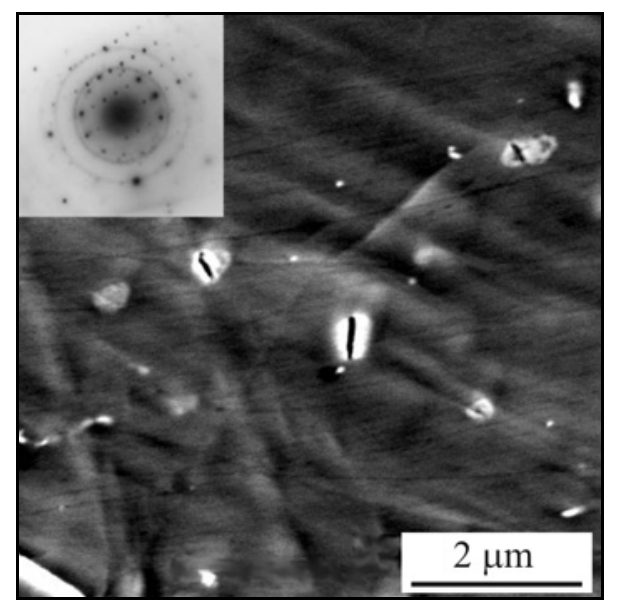

Fig. 3. TEM photo and diffractogram of $\mathrm{Mg}_{17} \mathrm{Al}_{12}$ phase, the material after ECAP.

comparison with the grain size of the starting experimental material the grain size after ECAP decreased to the values of ca $0.7 \mu \mathrm{m}$. The mean size was estimated by the measurement of 50-100 grains. Fine $\mathrm{Al}_{2} \mathrm{O}_{3}$ particles observed by TEM were distributed randomly as well as in clusters, Fig. 2. $\mathrm{Al}_{2} \mathrm{O}_{3}$ particles sized of ca $20 \mathrm{~nm}$ and their clusters were localised on the grain boundaries and in the grains. Obtained results are in good agreement with [4].

Transmission electron microscopy and selective electron diffraction showed the presence of spherical $\mathrm{Mg}_{17} \mathrm{Al}_{12}$ phase; the mean particles size was $0.3 \mu \mathrm{m}$, Fig. 3. These results are in good agreement with [12-14]. This phase has a body centred cubic crystal structure with the lattice parameter $a=10.569 \AA$. $\mathrm{Mg}_{17} \mathrm{Al}_{12}$ particles were distributed preferentially on the high angle grain boundaries and inhibited the grains growth.

Analyses of the deformation behaviour were per-

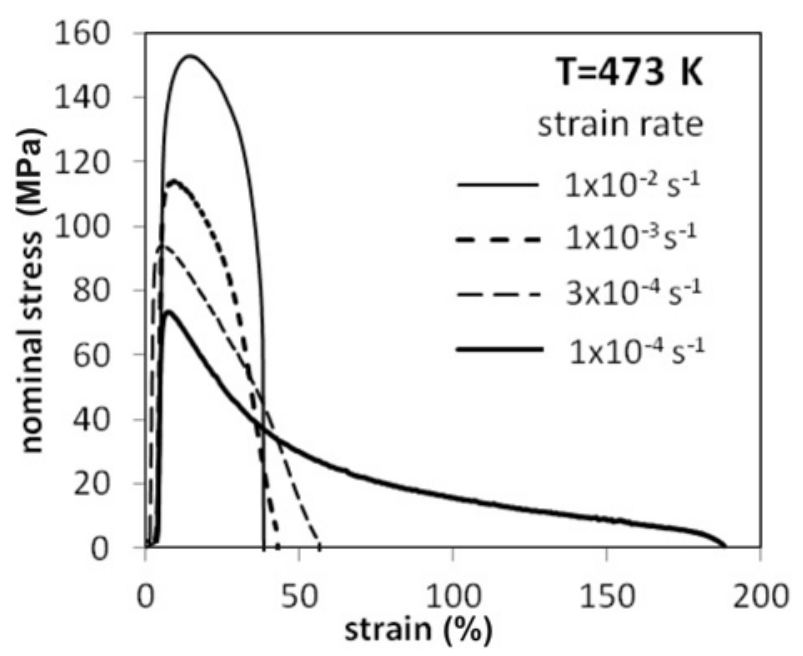

Fig. 4. Nominal stress vs. true strain at $473 \mathrm{~K}$ for samples with $1 \%$ of $\mathrm{Al}_{2} \mathrm{O}_{3}$ phase pressed by 4 passes.

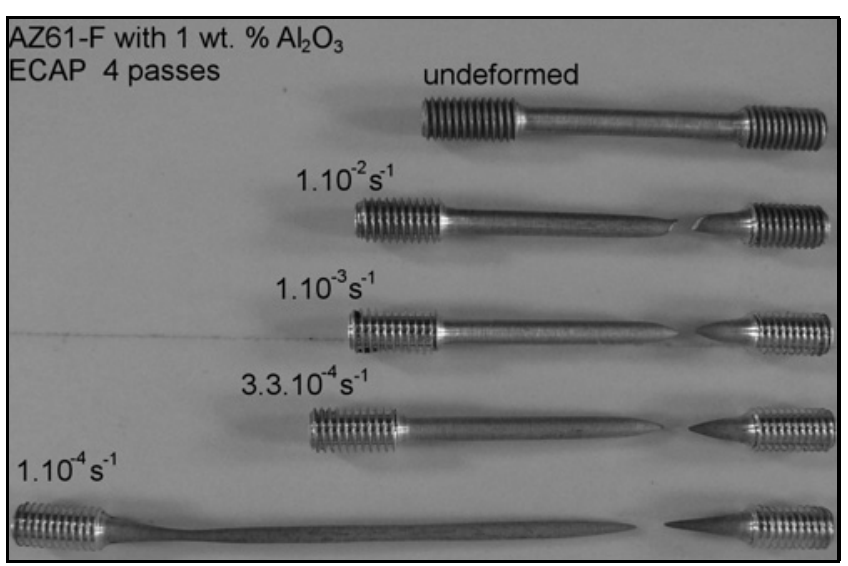

Fig. 5. Test specimens of AZ61-F with $1 \%$ of $\mathrm{Al}_{2} \mathrm{O}_{3}$ phase after deformation by different strain rates at $473 \mathrm{~K}$.

formed by the tensile deformation at temperatures $473 \mathrm{~K}$ and strain rates of $10^{-2}-1 \times 10^{-4} \mathrm{~s}^{-1}$, Fig. 4 . It was found that the experimental material had maximal elongation $180 \%$ at a temperature of $473 \mathrm{~K}$ and strain rate of $1 \times 10^{-4} \mathrm{~s}^{-1}$ what is in agreement with $[13,15]$ for the commercial alloy AZ61Mg. Lower values of the plasticity, in comparison to work [4], were caused by the presence of small $\mathrm{Al}_{2} \mathrm{O}_{3}$ and $\mathrm{Mg}_{17} \mathrm{Al}_{12}$ particles, which influenced fracture mechanism. A probable mechanism of superplasticity is the high angle grain boundary sliding. Strength properties decreased with the higher test temperature.

Figure 5 shows the specimens tested at the smaller rates pull out to a point. It was a proof of macroscopic necking within gauge lengths. It was well established that this behaviour represents a true superplastic condition.

Fracture micromechanisms were analysed over the strain rates range at a temperature of deformation 

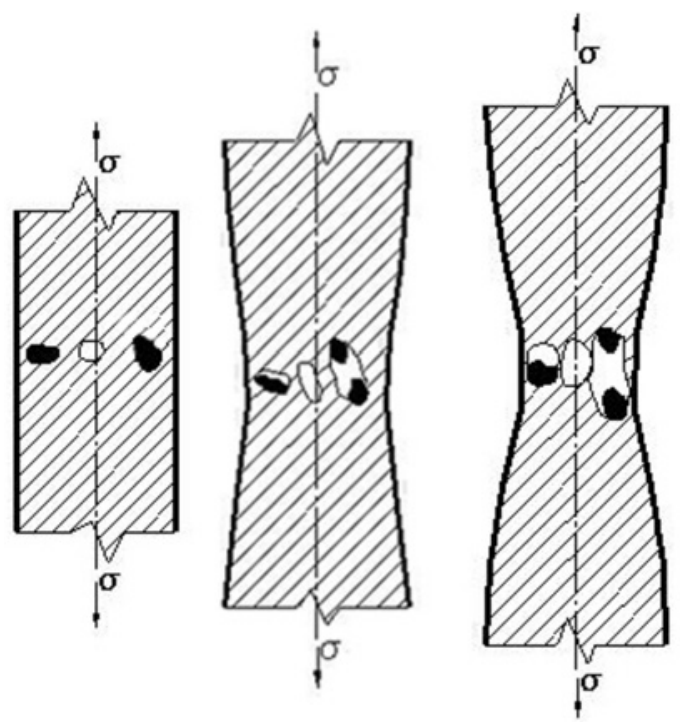

Fig. 6. Three stages of transcrystalline ductile fracture: (a) decohesion, (b) cavities, and (c) brittle particles.

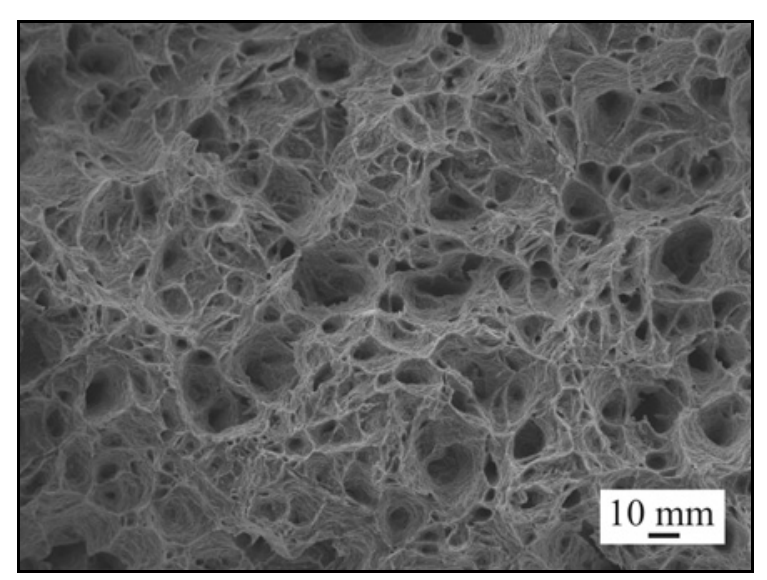

Fig. 7. Transcrystalline ductile fracture at $473 \mathrm{~K}$ and strain rate of $10^{0} \mathrm{~s}^{-1}$

of $473 \mathrm{~K}$. Fractures had the transcrystalline ductile dimple character. The mean diameter of dimples was evaluated from the file of 150-200 dimples. Larger dimples $(10 \mu \mathrm{m})$ were created on $\mathrm{Mg}_{17} \mathrm{Al}_{12}$ particles, smaller ones on the dispersed $\mathrm{Al}_{2} \mathrm{O}_{3}$ particles (dimples ca $0.7 \mu \mathrm{m}$ in diameter). According to Gurland-Plateau theory [16], the ductile fracture has three stages: initiation, growth and coalescence of cavities, Fig. 6 . Cracks were created on the particle-matrix interphases and presumably in the triple junctions of the grains of the matrix [17].

Fractures for each strain rate are shown in Figs. 7 11, the dependence of the dimples diameter on the strain rate is plotted in Fig. 12. The dependence is hyperbolic; the mean dimple diameter decreased with decreasing strain rate and at the constant tempera-

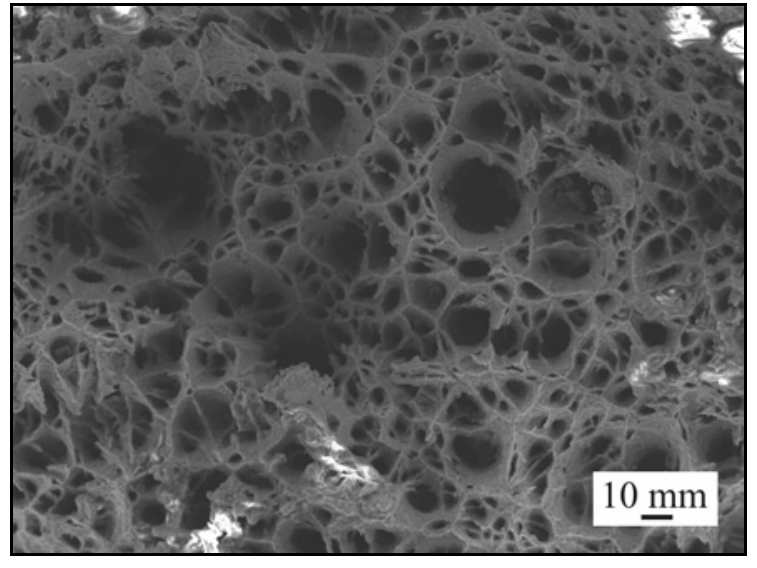

Fig. 8. Transcrystalline ductile fracture at $473 \mathrm{~K}$ and strain rate of $10^{-1} \mathrm{~s}^{-1}$.

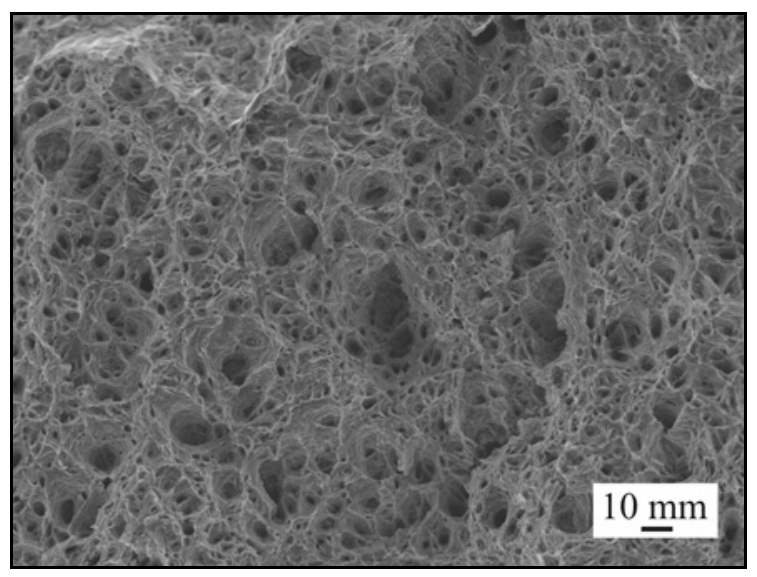

Fig. 9. Transcrystalline ductile fracture at $473 \mathrm{~K}$ and strain rate of $10^{-2} \mathrm{~s}^{-1}$.

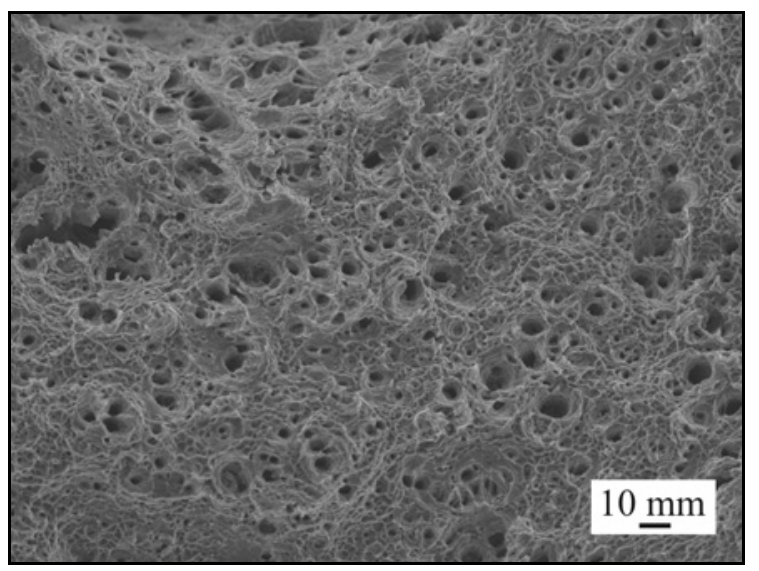

Fig. 10. Transcrystalline ductile fracture at $473 \mathrm{~K}$ and strain rate of $10^{-3} \mathrm{~s}^{-1}$.

ture $(473 \mathrm{~K})$. It is evident that besides decohesion on the particles $\left(\mathrm{Mg}_{17} \mathrm{Al}_{12}\right.$ and $\left.\mathrm{Al}_{2} \mathrm{O}_{3}\right)$ - matrix inter- 


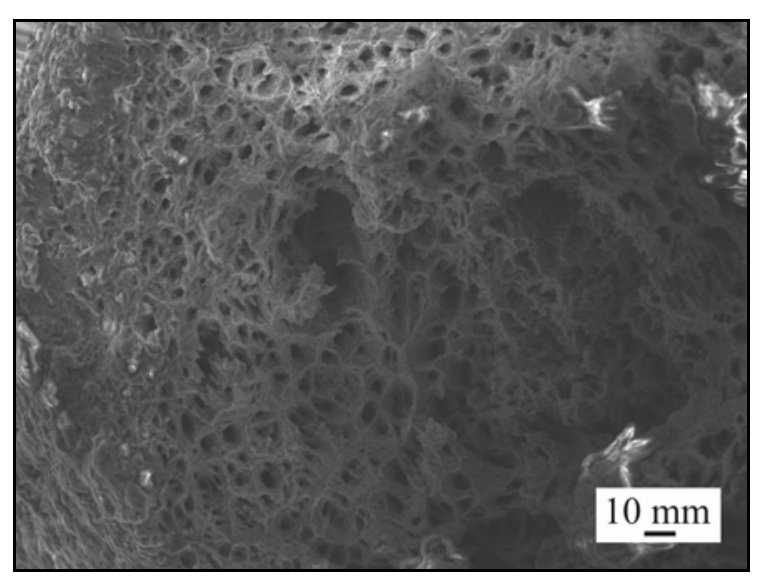

Fig. 11. Transcrystalline ductile fracture at $473 \mathrm{~K}$ and strain rate of $10^{-4} \mathrm{~s}^{-1}$.

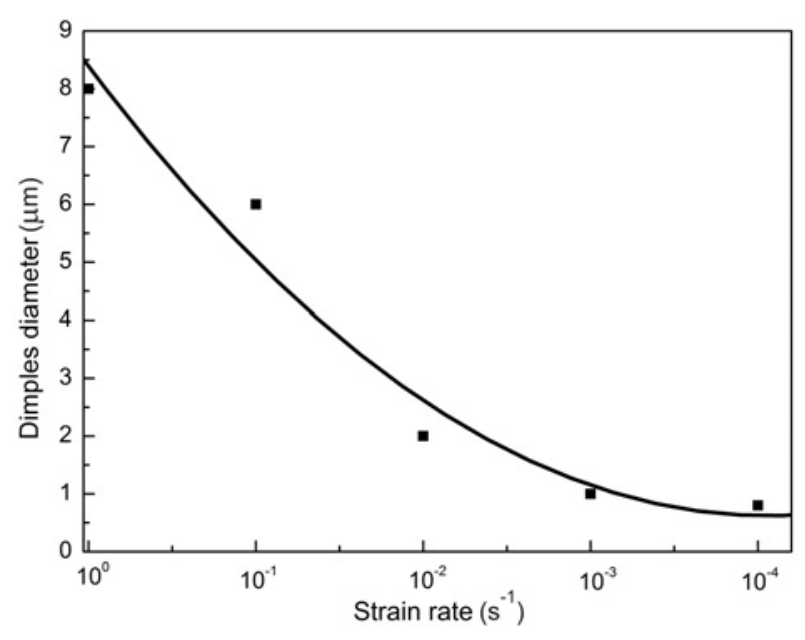

Fig. 12. Dependence of dimples diameter on strain rate.

phases, dimples were initiated in the triple junctions of nanomaterials. The growth of initiation centres led to growth reduction of the mean dimple size and high reduction of area.

\section{Conclusions}

Based on the extensive experimental studies of the kinetics of deformation of $\mathrm{AZ} 61 \mathrm{Mg}-\mathrm{Al}_{2} \mathrm{O}_{3}$ composites the following results were obtained:

- The mean grain size of the experimental material with 1 wt.\% of $\mathrm{Al}_{2} \mathrm{O}_{3}$ after ECAP by 4 passes was $0.7 \mu \mathrm{m} . \mathrm{Mg}_{17} \mathrm{Al}_{12}$ and $\mathrm{Al}_{2} \mathrm{O}_{3}$ particles of secondary phases were identified by TEM.

- The max. value of elongation ca $180 \%$ was reached at the temperature of $473 \mathrm{~K}$ and strain rate of
$1 \times 10^{-4} \mathrm{~s}^{-1}$. A probable mechanism of deformation is the high angle grain boundary sliding.

- The fracture at maximum values of quasisuperplasticity was transcrystalline ductile with dimples of two size categories. Based on the statistical analysis of fracture micromechanisms at the temperature of $473 \mathrm{~K}$ and strain rates of $10^{0}-1 \times 10^{-4} \mathrm{~s}^{-1}$ hyperbolic dependence was depicted $d_{\mathrm{j}}=f(\dot{\varepsilon})$.

\section{Acknowledgement}

The work was supported by the Slovak National Grant Agency under the Project VEGA 2/0080/17.

\section{References}

[1] Iwahashi, Y., Horita, Z., Nemoto, M., Langdon, T. G.: Acta Mater., 46, 1998, p. 3317. doi:10.1016/S1359-6454(97)00494-1

[2] Xu, C., Furukawa, M., Horita, Z., Langdon, T. G.: Acta Mater., 53, 2005, p. 749. doi:10.1016/j.actamat.2004.10.026

[3] Kawasaki, M., Langdon, T. G.: Acta Mater., 53, 2005, p. 5353. doi:10.1016/i.actamat.2005.08.012

[4] Miyahara, Y., Horita, Z., Langdon, T. G.: Mat. Sci. Eng. A, 420, 2006, p. 240. doi:10.1016/j.msea.2006.01.043

[5] Cao, G., Choi, H., Oportus, J., Konishi, H., Li, X.: Mat. Sci. Eng. A, 494, 2008, p. 127. doi:10.1016/j.msea.2008.04.070

[6] Ugandhar, S., Gupta, M., Sinha, S. K.: Composite Structures, 72, 2006, p. 266. doi:10.1016/i.compstruct.2004.11.010

[7] Hassan, S. F., Gupta, M.: J. of Alloys and Compounds, 419, 2006, p. 84. doi:10.1016/i.jallcom.2005.10.005

[8] Hassan, S. F., Gupta, M.: Mat. Sci. Eng. A, 392, 2005, p. 163. doi:10.1016/j.msea.2004.09.047

[9] Shanthi, M., Tun, K. S., Pandey, R. S., Gupta, M.: Kovove Mater., 49, 2011, p. 197. doi:10.4149/km 20113197

[10] Lin, P. Ch., Huang, S. J., Hong, P. S.: Acta Metallurgica Slovaca, 16, 2010, p. 237.

[11] Mukherjee, A. K., Bird, J. E., Dorn, J. E.: Trans. Am. Soc. Met., 62, 1969, p. 155.

[12] El-Morsy, A., Ismail, A., Waly, M.: Mat. Sci. Eng. A, 486, 2008, p. 528. doi:10.1016/j.msea.2007.09.044

[13] Matsubara, K., Miyahara, Y., Horita, Z., Langdon, T. G.: Metall. Mater. Trans. A, 35, 2004, p. 1735. doi:10.1007/s11661-004-0082-z

[14] Akyüz, B.: Kovove Mater., 52, 2014, p. 255. doi:10.4149/km 20145255

[15] Miyahara, Y., Matsubara, K., Horita, Z., Langdon, T. G.: Metall. Mater. Trans. A, 36, 2005, p. 1705. doi:10.1007/s11661-005-0034-2

[16] Gurland, J., Plateau, J.: Trans. ASM, 56, 1963, p. 442.

[17] Besterci, M., Sülleiová, K., Kvačkaj, T.: Kovove Mater., 46, 2008, p. 309. 